\title{
Características geográFicas Generales dE LA RESERVA NATURAL LAGUNA DE APOYO
}

Berta Adilia Mena García*

\begin{abstract}
Resumen
Reunir las características geográficas de un área catalogada como reserva natural resulta de interés para conocer mejor e interpretar la estrecha relación que existe entre la naturaleza y la sociedad. Y más aun cuando la calidad del paisaje se oferta a una creciente presión demográfica.
\end{abstract}

El presente trabajo forma parte de la investigación en la Reserva Natural Laguna de Apoyo como resultado de numerosos trabajos de campo y gabinete; el cual integra primero la ubicación geográfica de la imponente y misteriosa Laguna de Apoyo localizada en el centro de la Cordillera Volcánica del Pacifico nicaragüense, espacialmente bien estudiado por científicos en coordinación con MARENA INETER y AMICTLAN, luego se abordan los limites y categorías de manejo, seguidamente se presentan las comarcas que conforman los municipios circunvecinos a la laguna cratérica, ellos evocan la territorialidad y el amor que las personas profesan al terruño que los vio nacer, para cuidar y proteger el legado patrimonial. Luego, se presentan brevemente el aspecto climático, la economía, las características de las diferentes unidades geomorfológicas estudiadas. Finalmente, se refiere al uso actual del suelo, clasificación tabular y mapa sirven para verificarlo, luego destacan ejemplos de la biodiversidad representativa y la accesibilidad al área protegida.

La observación y el análisis a las diversas manifestaciones naturales y culturales de las poblaciones visitadas, aportaron abundantes ejemplos de la vida cotidiana, ellas merecen ser estudiados a mayor detalle debido a la dinámica realidad geográfica física y económica de nuestro país y el mundo.

Palabras claves: Características geográficas de la RNL, Geografía y reservas naturales, Geomorfología, Población en RNLA, Investigación en áreas protegidas.

Key words: Geographycal characteristics of the RNL, Geography and natural resources, geomorphology, population in RNLA, protected areas research.

* MS.c Docente Departamento. de Geografía UNAN Managua, Facultad de Humanidades y Ciencias Jurídicas 


\section{Introducción}

La Laguna de apoyo es una unidad paisajística que constituye un gran atractivo eco - turístico convirtiéndose en uno de los sitios más visitado de Nicaragua, tanto por turistas nacionales como por extranjeros de diversas nacionalidades.

La Laguna de Apoyo, además de pertenecer a la categoría de área protegida, por su ubicación en el centro del Pacífico nicaragüense, es una de las más concurridas, y sirve de referencia para la recreación en general. Su relevancia hoy en día, trasciende internacionalmente, pues se destaca como destino turístico y para diversas investigaciones científicas. Un gran atractivo paisajístico, presentan los miradores de Catarina, Diriá, Pacaya y Diriomito, donde cientos de visitantes asisten para disfrutar del ambiente acogedor. La demanda turística aumenta en el verano, cuando miles de personas visitan las playas cada año.
Se han realizado estudios geológicos, geomorfológicos, volcánicos, agroforestales, flora y fauna silvestre, por parte de diversas instituciones tales como AMICTLAN, ONGs, MARENA, UNAN y otros. Sin embargo, en el aspecto turístico son pocas las elaboraciones que se han presentado para el fortalecimiento de los planes del desarrollo a escala local y municipal.

Por tanto, la referencia geográfica física existente para la Reserva Natural Laguna de Apoyo (RNLA), junto al análisis eco turístico que se presentan en este artículo, proporcionan elementos que ayudan a comprender el espacio circundante en la identificación de vulnerabilidades naturales y sociales para la conservación.

\section{Ubicación, límite y categoría de manejo.}

El área de estudio comprende $91 \mathrm{~km}^{2}$ de la RNLA la que se ubica en la región

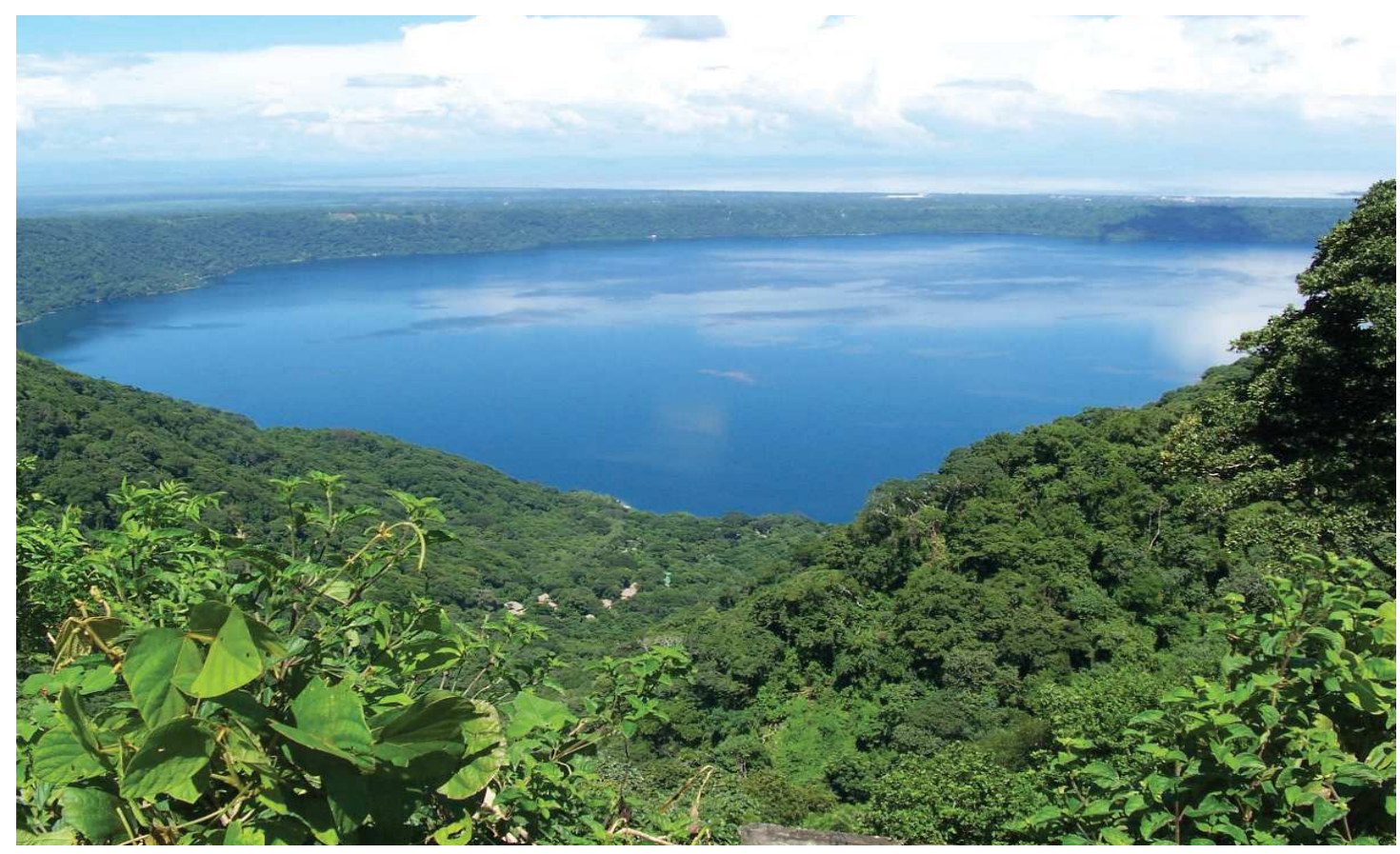


del Pacifico de Nicaragua entre los departamentos. de Masaya y Granada.

Lalaguna de Apoyo (atl-poyec: quesignifica "agua salobre"), ocupa el fondo de una antigua caldera de explosión y hundimiento que se formó hace unos 21,000 años, según su historia y vulcanología. El diámetro de la caldera, mide aproximadamente $6 \mathrm{~km}$. Y la profundidad estimada es de $200 \mathrm{mts}$., sin contar las paredes superiores de la caldera. La erupción del volcán, debió arrojar al espacio, millones de metros cúbicos de material de pómez, mayoritariamente durante sus repetidas explosiones, consideradas las más grandes acontecidas en nuestro país y que actualmente conforman los terrenos fértiles de los alrededores.

La Reserva Natural Laguna de Apoyo, se reconoce legalmente como Área Protegida por el Decreto 42-91 (1991) que permite a MARENA categorizar su manejo.

AMICTLAN mediante el Decreto 1320 (1983), declara a la Laguna de Apoyo como Reserva Natural, categoría de protección vigente en la actualidad. Define la extensión de la zona de protección de RNLA en 3500 hectáreas, sin aplicar límites cartográficos.

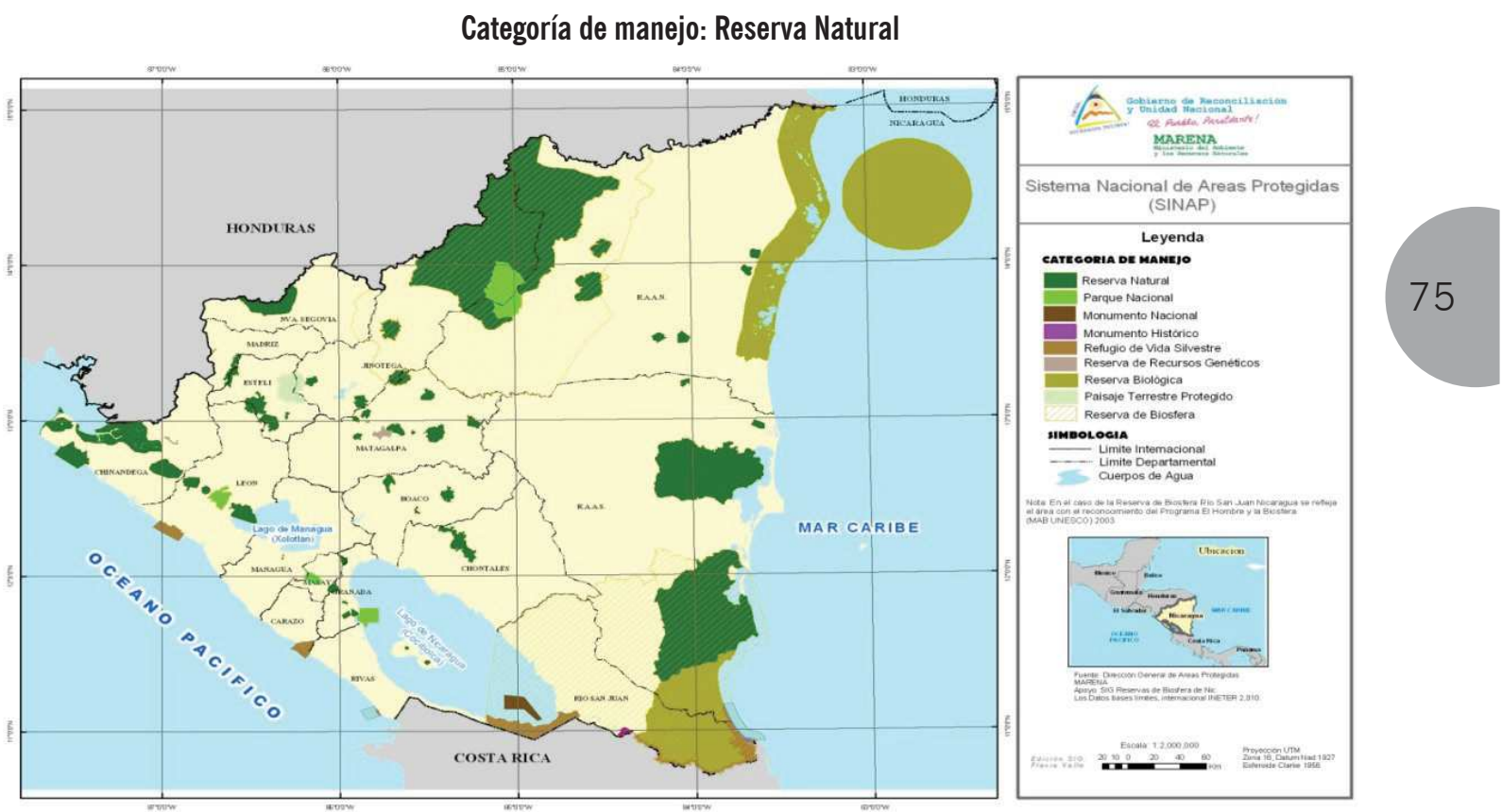

AMICTLAN en su documento, no propone límites, pero plantea como propósitos "beneficiar la conservación de los ecosistemas naturales que contengan y frenen el deterioro de las cuencas, la erosión en sus laderas y la destrucción de los manantiales que en ella se originan". Esto nos instruye sobre la importancia de garantizar la protección de los ecosistemas terrestres y lacustres, mencionados anteriormente y los manantiales pequeños que provienen de sus laderas interiores, en la selección de límites.

\section{Municipios y comarcas de la RNLA.}

Las alcaldías municipales implicadas en el Plan de Manejo, desconocen sus límites geográficos en relación a la Reserva. Por tanto, en base a los datos sobre límites 
disponibles (FUNDENIC 1999), se toma en cuenta el análisis de las consultas realizadas en siete municipios de los departamentos de Masaya y Granada. Las comarcas de la zona de amortiguamiento como también la ubicada dentro de la zona protegida. Pueden verse en el cuadro 1.

Cuadro 1. Municipios y Comarcas de la RNLA

\begin{tabular}{|c|c|c|c|}
\hline DEPTO & MUNICIPIO & $\begin{array}{l}\text { COMARCAS / ZONA DE } \\
\text { AMORTIGUAMIENTO }\end{array}$ & $\begin{array}{l}\text { COMARCA DENTRO DE } \\
\text { LA ZONA PROTEGIDA }\end{array}$ \\
\hline \multirow[t]{3}{*}{ GRANADA } & Diriomo & $\begin{array}{l}\text { Veracruz, Caña de Castilla, Guapinol, } \\
\text { El Rodeo, La Concepción, San Antonio, } \\
\text { La Fuente, Pilas Volteadas, Pedro } \\
\text { Arauz, Guanacaste y casco urbano del } \\
\text { municipio }\end{array}$ & \multirow{3}{*}{$\begin{array}{l}\text { Plan de la Laguna } \\
\text { Compartida con los } \\
\text { municipios de: } \\
\text { Diriá } \\
\text { Granada } \\
\text { Catarina } \\
\text { San Juan de Oriente }\end{array}$} \\
\hline & Diria & $\begin{array}{l}\text { Santa Elena y casco urbano del } \\
\text { municipio }\end{array}$ & \\
\hline & Granada & $\begin{array}{l}\text { El Chilamate, } \\
\text { La Laguna 1, } \\
\text { La Laguna 2, Valle de la Laguna, El } \\
\text { Capulín y El Sitio. }\end{array}$ & \\
\hline \multirow{4}{*}{ MASAYA } & Catarina & $\begin{array}{l}\text { Pacaya, Diriomito (sector Sur), El } \\
\text { Valle, Campo Alegre, Santa Rita y } \\
\text { Casco urbano del municipio. }\end{array}$ & \\
\hline & Niquinohomo & Tierra Blanca & \\
\hline & $\begin{array}{l}\text { San Juan } \\
\text { de Oriente }\end{array}$ & $\begin{array}{l}\text { Buena Vista, El Castillo y Casco } \\
\text { urbano del municipio }\end{array}$ & \\
\hline & Masaya & $\begin{array}{l}\text { Valle de la laguna, Pacaya, Pacayita, } \\
\text { Quebrada Honda, La Ermita, La Poma, } \\
\text { El Hatillo, El Aguacatillo, El Túnel, El } \\
\text { Mojón y Los Sabogales. }\end{array}$ & \\
\hline
\end{tabular}

\section{Clima}

El tipo de clima predominante en la región del Pacifico, es el de Sabana Tropical, según clasificación de Koppen (2005). Esta región presenta una marcada estación seca, entre los meses de noviembre a abril, y una estación lluviosa de mayo a octubre. La precipitación anual media varia de $900 \mathrm{~mm}$ a 2,200 mm, siendo los meses más lluviosos mayo y octubre (INETER: 1971- 2000).
La temperatura oscila entre 25 a $29^{\circ} \mathrm{C}$. y la precipitación anual promedio es de aproximadamente $1500 \mathrm{~mm}$. El tiempo climático que se percibe, es modificado por el viento que fluye de este a oeste, el cual refresca el ambiente en los alrededores de la caldera. El clima es de tipo tropical con transición a húmedo.

Localmente, los Pueblos Blancos son favorecidos por un microclima propio de la 
meseta de Carazo o de los Pueblos. Se define como clima semihúmedo, de sabana tropical, con una temperatura promedio de $27^{\circ}$, según datos de las estaciones meteorológicas del INETER situados en la zona. Las precipitaciones promedio registradas en Granada son de 1,212 mm (1973-1999). Ver cuadro 2.

Cuadro 2. Datos de Precipitación en Estaciones Alrededor de la RNLA

\begin{tabular}{|l|l|c|c|}
\hline Período & Estación & m.s.n.m. & $\begin{array}{c}\text { Precipitación } \\
\text { Media / anual }\end{array}$ \\
\hline $1973-1999$ & Granada & 50 & 1212 \\
\hline $1977-2005$ & Masaya & 210 & 1321 \\
\hline $1983-2006$ & Masatepe & 470 & 1418 \\
\hline $1994-2004$ & Catarina & 400 & 1452 \\
\hline $1967-2005$ & Santa Teresa & 630 & 1704 \\
\hline
\end{tabular}

Fuente: INETER

\section{Economía y densidad poblacional}

La economía de los municipios que conforman la RNLA, se basan en la producción de frutas legumbres, granos básicos, café, artesanía en cuero madera, palma, desarrollo industrial, plantas ornamentales, cerámica, turismo ganadería, cosecha de tabaco, cereales y caña de azúcar, y otras actividades. De manera general, se calcula que 218,000 habitantes residen en los municipios que conforman la RNLA (INEC: 2006).

\section{Aspectos geomorfológico}

La Laguna de Apoyo se encuentra alineada sobre la falla volcánica del Pacifico de Nicaragua y se ubica entre los volcanes Masaya y Mombacho. La caldera tiene forma circular, con paredes bajas y verticales hacia el este, más altas y extendidas al oeste, particularidad que revela que las explosiones expulsaron los materiales lávicos, hacia el suroeste donde se encuentra la mayor acumulación: en el Mirador de Catarina y el Cerro Pacaya. En sus alrededores, se localizan grandes

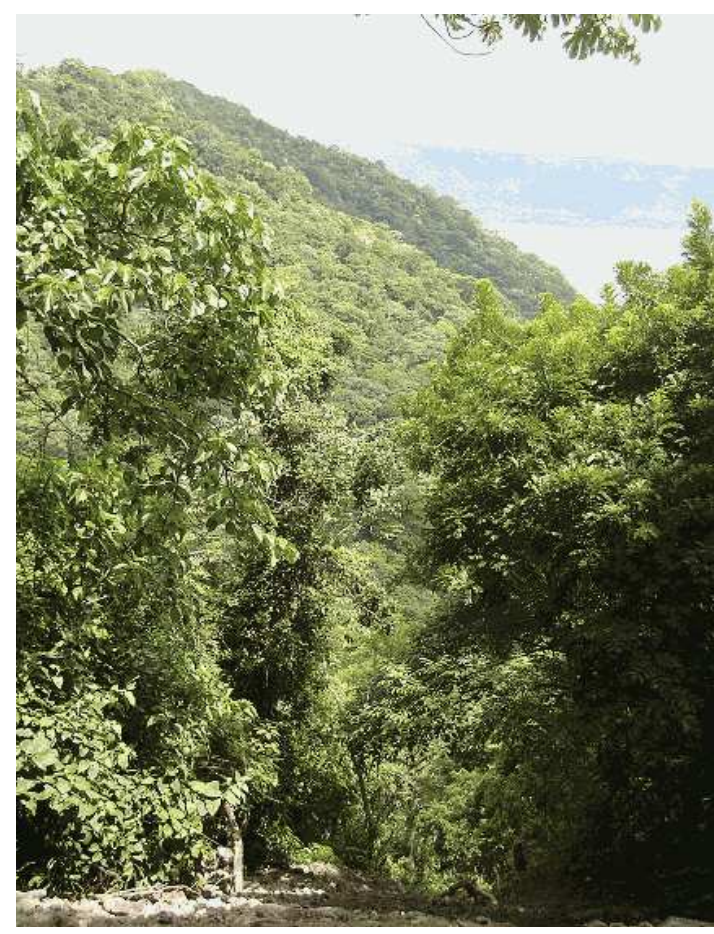

depósitos de pómez, así como también delgadas capas, en la llanura de Managua.

En la rivera occidental de la laguna, se observa lava solidificada al contacto con el agua, posiblemente proyectadas en etapas posteriores a la gran erupción del 
tipo Krakatoa. Edafológicamente, las laderas internas de Apoyo, están formadas por capas superpuestas de antiguos piroclastos, de fácil remoción por erosión y protección con cobertura vegetal. Además, se encuentran incrustados grandes bloques basálticos procedentes de la violenta erupción que dio origen a la caldera. Las laderas externas son tendidas y recubiertas de capas de piedra pómez, cuya fragilidad han dado lugar a la formación de cañadas y hondonadas en la parte norte y sur; las cárcavas se van ensanchando en la medida que se van deforestando los terrenos para la agricultura.

Desde el punto de vista geomorfológico, Nicaragua se divide en cinco provincias (Mc Birney \& Williams: 1965): Planicie costera del Pacífico; Cordillera volcánica del Pacifico; Depresión Nicaragüense; tierras altas del Interior; Planicie costera del Atlántico Caribe. Las tres primeras comprenden la región del Pacifico con una superficie de aproximadamente 38,700 $\mathrm{km}^{2}$, equivalente a un $30 \%$ de la superficie total del país.

Elárea en estudio, se localiza en la Cordillera Volcánica del Pacifico, constituida por una cadena de volcanes del cuaternario al reciente, de orientación N.O.-S.E. con $300 \mathrm{~km}$ de longitud. Se extiende, desde el Volcán Cosigüina al NO, hasta el Volcán Maderas (Isla de Ometepe) en el lago de Nicaragua, al SE. La parte de la cadena comprendida entre el Volcán San Cristóbal y el Momotombo, se denomina Cordillera de los Maribios, con una elevación máxima de 1745 m en el Volcán San Cristóbal. Entre el escarpe de Mateare y el Volcán Madera, la cadena se llama cordillera del Pacifico y la mayor elevación se ubica en el Volcán Concepción. Laguna de apoyo, en la zona central de la provincia fisiográfica de la cordillera volcánica, constituye relieves en forma de valles y elevaciones topográficas que van desde los 70 m.s.n.m. hasta los 500.s.n.m.m

Según el marco geológico regional, el estudio realizado identificó 16 diferentes unidades geomorfológicas según su origen:

I. Unidades de Origen Denudatorio propuesta como (Zona de amortiguamiento)

1. Ladera suave de meseta. Zona de transición, la cual va desde el borde de la caldera hasta las zonas más planas, situadas en los extremos del área. Se extiende desde el municipio de San Juan de Oriente hasta la zona de Masaya. Estas se han ido erosionando, creando pendientes más suaves.

2. Peniplanicie. Zona oriental fuera de la caldera, Relieve ondulado. Topografía cortada por drenajes que van hacia el lago de Nicaragua, pasando por Granada. Relieve con largo periodo de erosivo.

\section{Unidades de Origen Estructural:}

1. Escarpes por Movimiento de Masa: Están definidos por las paredes con fuertes pendientes, las cuales han sido generadas por fenómenos de inestabilidad en laderas, erosión o cualquier otro movimiento que modifica el relieve. Esta tipología, está localizada de forma continua, alrededor del borde de la caldera formando una subunidad de Escarpe de caldera. Estas crean una secuencia de escarpes cóncavos, en semicírculo, que son de grandes dimensiones en el borde oeste y sur (Catarina, San Juan de Oriente y Diriá) y más numerosos pero de menores dimensiones en el borde este (municipio de Granada).

Los escarpes van retrocediendo por fenómenos de inestabilidad en laderas, 
debido a los factores condicionantes (geología, pendiente, geomorfología) y los factores desencadenantes (precipitaciones y sismos, se encuentran desprovistos de vegetación.

3. Laderas de fallas. Pendientes moderadas de origen estructural, que representan el desplazamiento de fallas. Son estructuras susceptibles de generar desplazamientos y en las cuales están concentrados los flujos de detritos. Estas laderas, presentan una pendiente mayor de $30^{\circ}$, comenzando estas al borde de la caldera.

En la parte sur del área de estudio, correspondiente al municipio de Diriá y Diriomo, se presentan laderas con una expresión geomorfológica en forma de escalones.

\section{Unidad de Origen Volcánico}

1. Domos volcánicos. Existe en el área propuesta de amortiguamiento de la RNLA, en el municipio de Diriomo, tres elevaciones redondeadas muy significativas. La de mayor elevación, con 420 m.s.n.m., es llamada "El Cerrito" y está acompañado de otra colina de 340 m.s.n.m. "El Cerritito", situada a pocos cientos de metros. La otra elevación está situada en el centro de una pequeña estructura en caldera que pertenece a la unidad de relieve relicto Pre Apoyo, cerca del mirador de Veracruz. Originadas por erupciones de tipo peleano, donde la lava, de composición muy acida, no se puede extender en coladas como la lava basáltica, sino que forma una estructura que tiende a crecer en la vertical llamada domos, alineados a fallas.

2. Conos Cineríticos. Esta unidad agrupa a los cerros, cuyo origen es la acumulación de piroclastos (normalmente escorias, llamadas localmente "hormigón"), debido a repetida erupciones volcánicas de tipo estromboliano. En la zona propuesta de amortiguamiento de la RNLA, se encuentran dos cerros. Uno de ellos, el cero Pacaya (Catarina) supone la mayor elevación del área, con 620 m.s.n.m. El otro, Cerro el Chanal con una altura de 180 m.s.n.m., forma parte de los cerros ubicados en el municipio de Granada, asociados al lineamiento Granada-Nandaime.

3. Relieve relicto volcánico. En la zona de Diriomo, correspondiente a la parte sureste, próxima a la caldera, existe una zona bastante abrupta con elevaciones significativas, las que van desde 210 m.s.n.m. hasta 460 m.s.n.m. Este relieve, ha sido clasificado anteriormente como relictos erosionales Pre-Apoyo (Hradecký: 1998). Se ha interpretado a esta unidad geomorfológica, como el relieve erosionado del volcán o de uno del estrato-volcanes que existieron antes del colapso de Apoyo.

El paisaje se presenta muy abrupto, debido a que la red de drenaje ha pasado miles de años surcando la estructura de roca dura del antiguo volcán, consiguiendo con mayor éxito erosionar las capas de ceniza y pómez tras el colapso.

4. Planicie intervolcánica. Unidad de paisaje definida por Van Zoidan, Robert (1975), se caracteriza por pendientes moderadas y topografía ondulada, corresponde al paisaje de planicie que separa el relieve volcánico abrupto relicto de Diriomo y las faldas del volcán Mombacho. 


\section{Unidades de Formación de Caldera y Estabilización de Laderas}

1. Las unidades relacionadas con el colapso de la caldera de Apoyo, y la posterior regulación de las laderas, han sido agrupadas es una categoría distinta. La rezón se debe a que el origen de este paisaje, es una combinación de diversos procesos, los cuales incluyen, origen volcánico (erupción explosiva que vació la cámara magmática), estructural (colapso de edificio volcánico a través de fallas y lineamientos preferenciales, generación de procesos de regulación de laderas a través de fracturación), erosivos y sedimentarios (erosión de zonas altas y acumulación de depósitos en las partes bajas).

2. Borde de caldera. Se trata de la zona externa a la caldera, situada inmediatamente adyacente al escarpe de caldera. Esta unidad geomorfológica no tiene una expresión claramente diferenciada en el paisaje, pero agrupa a los terrenos que tienen potencialidad de irse degradando mediante el retroceso del borde de la caldera, por procesos de inestabilidad de ladera y erosión. Esta zona está por lo tanto, expuesta a los procesos de erosión del escarpe y la dinámica propia de la caldera.
Ladera abrupta de caldera. Esta unidad se define para la parte más alta de la caldera Apoyo, donde las pendientes varían entre $30^{\circ}$ y $90^{\circ}$ (pared vertical). Se ve afectada constantemente por procesos erosivos y movimientos de masa. Dentro de esta unidad se ubican quebradas angostas con profundidades mayores de $30 \mathrm{~m}$.

3. Las laderas escarpadas, presentan morfologías típicas de colapsos volcánicos. Son cóncavas y largas en la parte de la caldera, correspondiendo a los municipios de San Juan de Oriente, Diriá y Catarina, y más cortas y rectilíneas, la parte este de la caldera, que corresponde al municipio de Granada, debido a la distinta composición litológica.

4. Ladera Suave de Caldera. En la ladera interna de Apoyo, se observa localmente un cambio bastante brusco de pendiente de alto a moderado. Esta unidad representa la ladera de caldera donde la pendiente es moderada. La morfología de las quebradas es menos profunda. Esta unidad es muy patente en el Plan de la Laguna (Catarina) y en San Juan de Oriente, siendo más estrecha en la zona Noreste (Catarina Granada) y en la Sur (Diria). En la zona este (Granada), esta unidad no está presente dado que la ladera es abrupta hasta la orilla de la laguna.

5. Zona de Acumulación de Movimiento de Masa. Gran parte de estos depósitos coluviales se acumulan en la Ladera Suave de Caldera, pero existen zonas que debido a la intensidad y frecuencia de la inestabilidades de la parte superior, en la que las acumulaciones son de un mayor orden, por lo que se les ha agrupado dentro de una unidad 
geomorfológica distinta a la de Ladera Suave de Caldera.

6. Un ejemplo es está al pie del cerro de la Ardilla en Diriá, donde se puede observar una acumulación de gran cantidad de bloques de roca, de varios metros de diámetro, dificultando, por su alta densidad, el transito a esa zona.

\section{Unidades de Origen Fluvio-Lacustre:}

1. Limite de erosión de quebrada. En el área de estudio, la erosión hídrica es un actor que tiene gran incidencia en el paisaje. La red de drenaje presente, es prácticamente radial, tanto dentro de la caldera como hacia afuera, donde la elevación relicta del volcán Pre-Apoyo provoca que el borde del cráter, funcione como la cabecera de todas las quebradas encontradas en el área de estudio. En este contexto, las quebradas presentes en la RNLA tienen la morfología típica de las zonas altas de cuencas, donde se produce una fuerte erosión, cuyos sedimentos serán depositados hacia la desembocadura.

2. En el caso de la zona externa del borde de la caldera, tenemos representada únicamente los tramos superiores de las quebradas, dado que la desembocadura se encuentra fuera del área de estudio. Las quebradas situadas dentro de la caldera tienen morfologías más rectilíneas, donde predomina la erosión del cauce en todo el trayecto, dado que normalmente no se produce un cambio de pendiente en la ladera, suficientemente brusco para que pase a dominar un ambiente más bien de depósito ( este se constata en las zonas donde existen abanicos aluviales). El depósito se produce en la laguna, donde se reduce bruscamente la velocidad del flujo.
3. Ladera abrupta de quebrada. Esta unidad geomorfológica la vemos representada principalmente en la zona externa de la caldera, en la zona oeste (Catarina, San Juan de Oriente y Diriá) y en el sector del sureste (sector de Veracruz y Guapinol en Diriomo), donde la acción erosiva de las quebradas, ha creado gran profundización, modelando alrededor del cauce laderas con pendientes entre $20^{\circ}-30^{\circ}$. En el municipio de Granada no se ha reconocido esta unidad dado que las quebradas son más planas.

4. Abanicos Aluviales Activos. Los abanicos aluviales o conos de deyección, son los que se generan después de que los flujos que recorren un frente montañoso o una angosta quebrada, llegan a una zona de pérdida de pendiente y ensanchamiento del cauce. En esas zonas, la velocidad del agua disminuye y se expande haciendo que los materiales arrastrados por el agua se sedimenten en forma de abanico.

5. Normalmente se produce una graduación de tamaños, de tal forma que los materiales más pesados se sedimentan primero y los más finos en la parte distal del abanico, en este caso en el propio lecho de la laguna. Los anchos promedios de los abanicos andan entre 35-60m. Estas áreas son zonas propensas a inundación.

6. Zona de Depósitos Lacustres. Esta unidad geomorfológica está asociada al proceso de disminución del nivel de la Laguna de Apoyo, la cual ha expuesto en la zona terminal de las laderas de la caldera, distintas terrazas de pequeño desarrollo, provocadas por distintos periodos de descenso de niveles. Las pendientes son suaves, de entre $0-10^{\circ}$, pero se ven bruscamente 
afectadas por relieves abruptos de las terrazas, entrando las más antiguas mas suavizadas por la acción erosivas. presente en todo el borde de la laguna, formada por sedimentos lacustres.

\section{Uso actual del suelo en el área protegida}

Según estimaciones del Ministerio de Agricultura y de los Recursos Naturales
(MARENA), la laguna cratérica abarca el $63.6 \%$ de su superficie; le sigue el bosque latifoliado alto y cerrado con el $21.9 \%$; en vegetación arbustiva, $07.5 \%$; en pastos y malezas, el $03.2 \%$; para los centros poblados, $03.4 \%$ del suelo. En cambio, en la periferia de $5 \mathrm{~km}$. a la redonda, predominan para los cultivos agrícolas el $64.8 \%$; y para el cultivo de café, musáceas y frutales el $14.4 \%$. Ver mapa y cuadro 3.

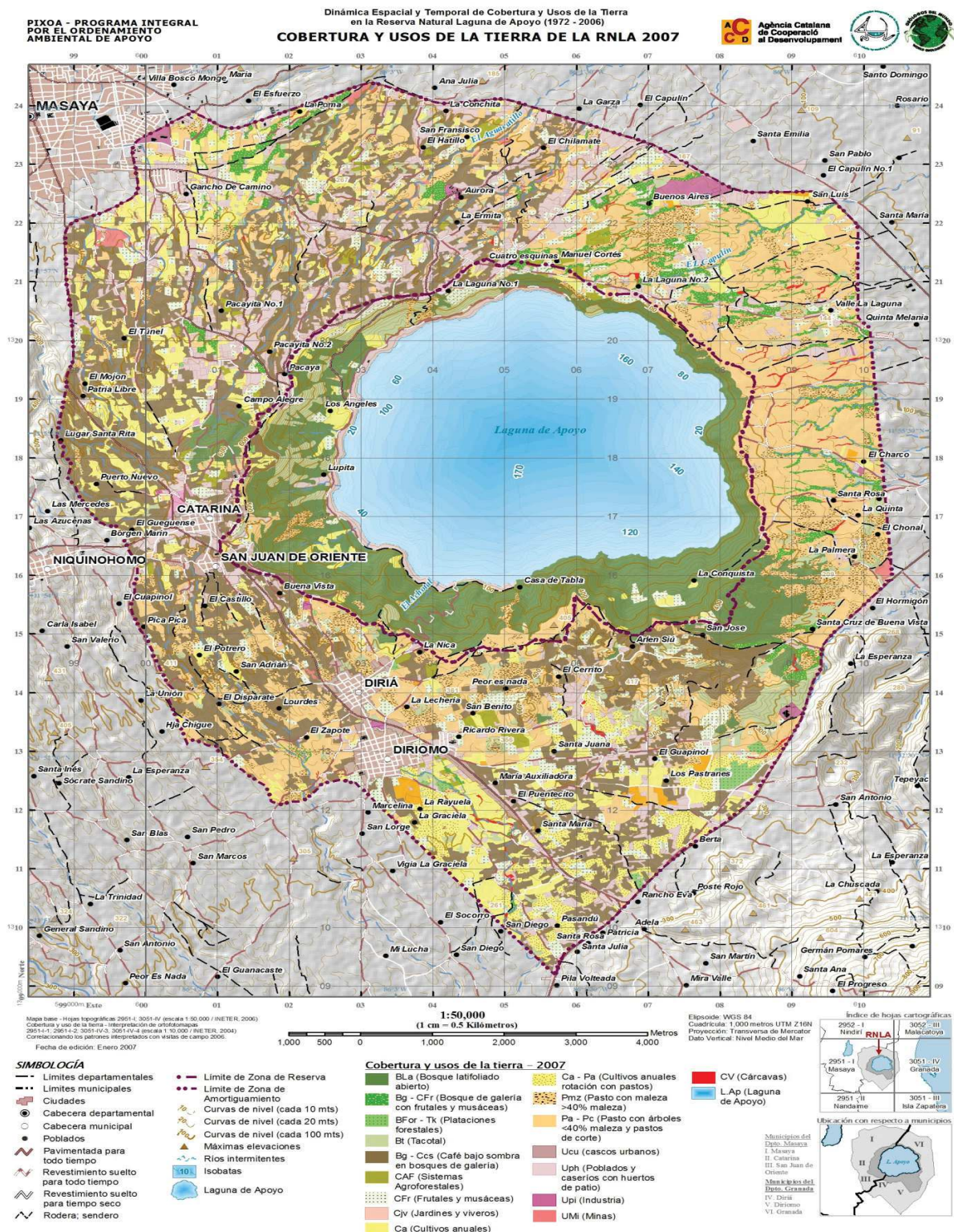


Cuadro 3. Clasificación de cobertura y usos de la tierra en la Reserva Natural Laguna de Apoyo

\begin{tabular}{|c|c|c|c|c|c|c|}
\hline Cobertura & Categorías & Subcategorías & Elementos abund & Otros elem & Uso Actual & Símbol \\
\hline \multirow{3}{*}{$\begin{array}{l}\text { B o s q u e s } \\
\text { medianos o } \\
\text { bajos sub } \\
\text { Caducifolios } \\
\text { de zonas } \\
\text { cálidas y semi } \\
\text { húmedas }\end{array}$} & \multirow[t]{2}{*}{$\begin{array}{l}\text { Bosque } \\
30 \%-70 \% \text { de } \\
\text { cobertura de copa }\end{array}$} & $\begin{array}{l}\text { Bosque Latifoliado } \\
\text { abierto }\end{array}$ & $\begin{array}{l}\text { Cachito } \\
\text { Jiñocuabo } \\
\text { Quebracho } \\
\text { Sardinillo } \\
\text { Guarumo } \\
\text { mango }\end{array}$ & $\begin{array}{l}\text { Madroño, malinche, } \\
\text { marañón, jocote jobo, } \\
\text { ceiba, pochote, } \\
\text { chilca, mamón }\end{array}$ & $\begin{array}{l}\text { Extracción de madera } \\
\text { Belleza escénica } \\
\text { Turismo }\end{array}$ & BLa \\
\hline & & Bosque de galería & $\begin{array}{l}\text { Guarumo, bambú, } \\
\text { musa spp., café, } \\
\text { guanacaste, mango }\end{array}$ & $\begin{array}{l}\text { Guayaba, ceiba, corozo, } \\
\text { níspero, } \\
\text { jiñocuabo, guácimo de } \\
\text { ternero. }\end{array}$ & $\begin{array}{l}\text { Producción de café, } \\
\text { plátano y frutales, } \\
\text { Extracción de leña y } \\
\text { bambú }\end{array}$ & $\mathrm{Bg}$ \\
\hline & $\begin{array}{l}\text { Re ge ne ración } \\
<30 \% \text { de cobertura } \\
\text { de copa }\end{array}$ & Tacotal & $\begin{array}{l}\text { Sardinillo, poroporo, } \\
\text { roble }\end{array}$ & $\begin{array}{l}\text { Sacuanjoche, chilamate, } \\
\text { malinche }\end{array}$ & $\begin{array}{l}\text { Leña, agricultura } \\
\text { migratoria }\end{array}$ & $\mathrm{Bt}$ \\
\hline \multirow{3}{*}{ Agrícola } & \multirow{3}{*}{$\begin{array}{l}\text { Sistemas perennes } \\
\text { o semiperennes } \\
15-30 \% \text { de } \\
\text { cobertura de copa }\end{array}$} & Café con sombra & $\begin{array}{l}\text { Café caturra } \\
\text { guanacaste, musáceas }\end{array}$ & $\begin{array}{l}\text { Chaperno, lagartillo, } \\
\text { jocote jobo, jiñocuabo, } \\
\text { chilamate, mamón, } \\
\text { acetuno }\end{array}$ & $\begin{array}{l}\text { Café para mercado } \\
\text { local, } \\
\text { Café en abandono }\end{array}$ & Ccs \\
\hline & & $\begin{array}{l}\mathrm{S} \text { i s } \mathrm{t} \text { e } \mathrm{m} \text { a } \mathrm{s} \\
\text { Agroforestales }\end{array}$ & $\begin{array}{l}\text { Mango, aguacate, } \\
\text { granos básicos }\end{array}$ & $\begin{array}{l}\text { Cítricos, coco y roble, } \\
\text { madero negro }\end{array}$ & $\begin{array}{l}\text { Obtención de frutas, } \\
\text { granos básicos y } \\
\text { madera }\end{array}$ & CAF \\
\hline & & $\begin{array}{l}\text { Frutales } \\
\text { Cítricos } \\
\\
\text { Aguacate } \\
\text { Mango } \\
\text { Jocote }\end{array}$ & $\begin{array}{l}\text { Naranja, limón dulce } \\
\text { Aguacate } \\
\text { Mango } \\
\text { Jocote }\end{array}$ & $\begin{array}{l}\text { Limón, limón Tahití, } \\
\text { mandarina }\end{array}$ & $\begin{array}{l}\text { Mercado nacional } \\
\text { Mercado nacional y } \\
\text { exportación }\end{array}$ & $\begin{array}{l}\text { CFr } \\
\text { CFr-Ct } \\
\\
\text { CFr-Ag CFr- } \\
\mathrm{Mg} \\
\text { CFr-Jt }\end{array}$ \\
\hline
\end{tabular}




\begin{tabular}{|c|c|c|c|c|c|c|}
\hline & & Musáceas & Plátano & Guineo cuadrado, banano & \begin{tabular}{|l|}
$\begin{array}{l}\text { Autoconsumo } \\
\text { mercado local }\end{array}$ \\
\end{tabular} & $\mathrm{CMu}$ \\
\hline & & Jardines y viveros & \multicolumn{2}{|l|}{ Ornamentales } & Mercado local & Cjv \\
\hline & \multirow{3}{*}{$\begin{array}{l}\text { Cultivos anuales o } \\
\text { estacionales }\end{array}$} & Granos básicos & Maíz, frijol, arroz & Sorgo & \multirow{2}{*}{$\begin{array}{l}\text { A u t o c o n s u m o, } \\
\text { mercado local, } \\
\text { épocas de siembra) }\end{array}$} & \multirow{3}{*}{$\mathrm{Ca}$} \\
\hline & & $\begin{array}{l}\text { Raíces, hortalizas y } \\
\text { tubérculos }\end{array}$ & Yuca, quequisque & Pipián & & \\
\hline & & Flores & \begin{tabular}{|l|} 
San Diego, botón, \\
disciplina, gladiola, \\
rosa poma, lirio
\end{tabular} & Mosaico & $\begin{array}{l}\text { Mercado local (fecha } \\
\text { óptima } 2 \text { de Nov.) }\end{array}$ & \\
\hline \multirow{3}{*}{ Pecuario } & \multirow[b]{2}{*}{ Pasto } & Pasto de corte & Taiwán & & $\begin{array}{l}\text { Alimentación de } \\
\text { ganado }\end{array}$ & Pc \\
\hline & & $\begin{array}{lr}\text { Pasto }<40 \% \text { de } \\
\text { matorrales } y \\
\text { malezas y algunos } \\
\text { árboles dispersos }\end{array}$ & \multirow{2}{*}{ Jaragua, estrella. } & \multirow{2}{*}{$\begin{array}{l}\text { Guácimo de ternera, } \\
\text { guácimo de molenillo, } \\
\text { guayaba, pochote, } \\
\text { jiñocuabo, genízaro } \\
\text { Eucalipto, cornizuelo }\end{array}$} & \multirow{2}{*}{$\begin{array}{l}\text { Ganadería extensiva } \\
\text { doble propósito. } \\
\text { Crianza de caballos } \\
\text { de raza, pelibuey, } \\
\text { cerdos y aves de } \\
\text { patio. } \\
\text { Pmz }\end{array}$} & $\mathrm{Pa}$ \\
\hline & Pasto con maleza & $\begin{array}{lr}\text { Pasto }>40 \% & \text { de } \\
\text { matorrales } & y \\
\text { malezas y algunos } & \\
\text { árboles dispersos } & \end{array}$ & & & & \\
\hline \multirow{3}{*}{$\begin{array}{c}\text { Área } \\
\text { humanizada }\end{array}$} & Urbano & Cascos urbanos & Mango, aguacate & Musáceas & Comercio, turismo & Ucu \\
\hline & Rural & $\begin{array}{l}\text { Poblados y caseríos } \\
\text { con huertos de patio }\end{array}$ & $\begin{array}{l}\text { Musáceas, mango, } \\
\text { mamón, aguacate, coco, } \\
\text { bambú }\end{array}$ & $\begin{array}{l}\text { Huertos de subsistencia } \\
\text { (granos básicos), } \\
\text { Frutales }\end{array}$ & $\begin{array}{|llll|}\text { C o m e r c i } & \text { o , } \\
\text { aserraderos y } & & \\
\text { Huertos } & & & \text { de } \\
\text { subsistencia } & & & \\
\end{array}$ & Uph \\
\hline & Infraestructuras & $\begin{array}{l}\text { Inf. Agrícolas e } \\
\text { industrias }\end{array}$ & Mangos, eucalipto & Forestales energéticos & \begin{tabular}{|l|}
$\begin{array}{l}\text { Gallineros, silos, } \\
\text { pómez }\end{array}$ \\
\end{tabular} & Ui \\
\hline $\begin{array}{c}\text { Cuerpos de } \\
\text { agua }\end{array}$ & Laguna cratérica & Laguna de Apoyo & Sardina & Mojarra & Recreación, pesca & L.Ap \\
\hline $\begin{array}{l}\text { Suelos sin } \\
\text { cobertura }\end{array}$ & Minas & Minas de pómez & Pómez & & Minería & Mip \\
\hline
\end{tabular}




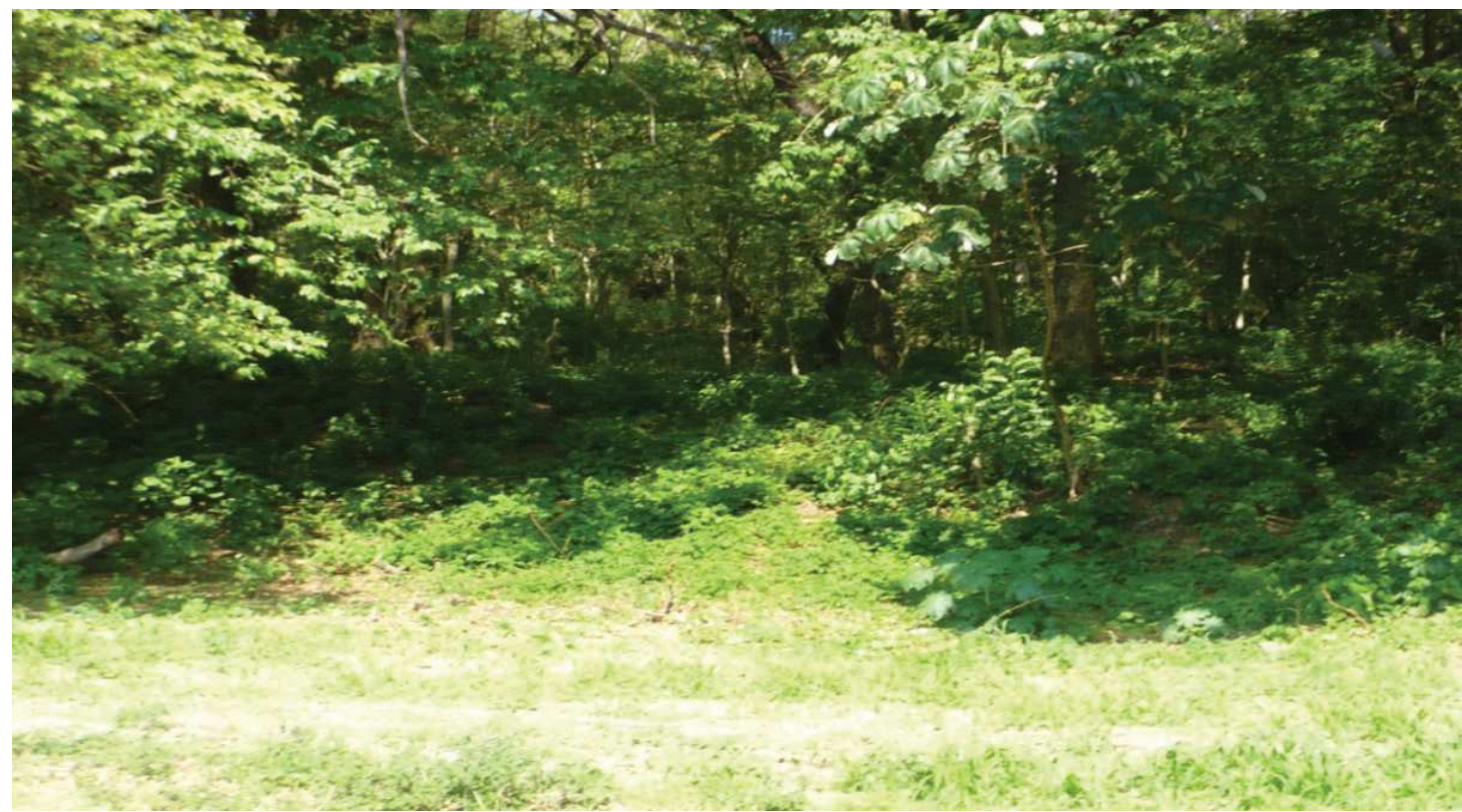

Aspecto del bosque por el mirador de Diriá.

\section{Flora}

El bosque en las paredes internas del cráter, presenta variable densidad. La exuberancia del bosque húmedo se encuentra en las laderas este y sur de la laguna, sin embargo, en la actualidad la mayoría de los sitios han sido talados para producir leña o para la siembra de cultivos en laderas. La tala atenta contra el bosque y la laguna, al quedar el suelo expuesto a la erosión y la sedimentación. Los bosques que se encuentran en las laderas norte, sur y oeste del cráter, han sido fuertemente intervenidos por actividades agrícolas y quemas frecuentes.

Se verifica que la vegetación que crece a la orilla de la laguna abunda en: sardinillo, guácimo, guarumos, aromo, ceiba, cedro tigüilote, genízaro, chaperno, jocote tempisque, gavilán, carao, chilamate, melero, madero negro, pochote, poroporo, mora, vainilla, madroño, quebracho, anona, capulín, panamá, achiote, aguijote, javillo, huevo de chancho, chilca montera, jalacate de monte, cinco negrito, chischil, jícama de monte, frijol chonete, serjania, batatilla, bellísima, uña de gato, selaginella, adiantum, zacate, conchita, begonia.

\section{Fauna}

En cuanto a la fauna, se han identificado algunas especies cíclicas, como guapotes, mojarras y también varios tipos de peces más pequeños. Siendo la laguna, un cuerpo de agua superficial situada en medio de una región carente de ríos y estando rodeada por un bosque de cierta densidad, resulta un buen hábitat para albergar fauna silvestre. Existe una población de monos congos y cara blanca que deambulan entre las copas de los árboles próximos a la laguna. También han sido reportadas guatusas, mapachines, pizotes $\mathrm{y}$ hasta venados.

No existen regulaciones ni controles para las actividades de cacería y la pesca en el 
sitio. La ornitofauna de la laguna, es muy variada, reportándose urracas, zanates, oropéndolas, salta piñuelas, guises, chichiltotes, cenzontles, guardabarrancos entre otras que son propias de la región del Pacifico.

El ecosistema acuático lacustre de la RNLA, oligotrófico y ligeramente salino, es especial por la transparencia de sus aguas. La presencia de varias especies endémicas, de peces en la laguna y las que evolucionaron dentro de esta, la convierten en un punto de gran valor para la biodiversidad y por tanto se le debe otorgar alta prioridad y protección continua a los hábitats.

\section{Accesibilidad, infraestructura y servicios.}

Las principales vías de acceso a cualquiera de estos municipios son: la carretera Panamericana, la cual que enlaza las ciudades de Masaya, Granada, Carazo y Managua y una extensa red de vías secundarias que unen las áreas rurales con las urbanas.

Se constata la existencia de los servicios públicos como el de transporte, salud, educación, energía eléctrica y agua potable para el beneficio de la población residente.

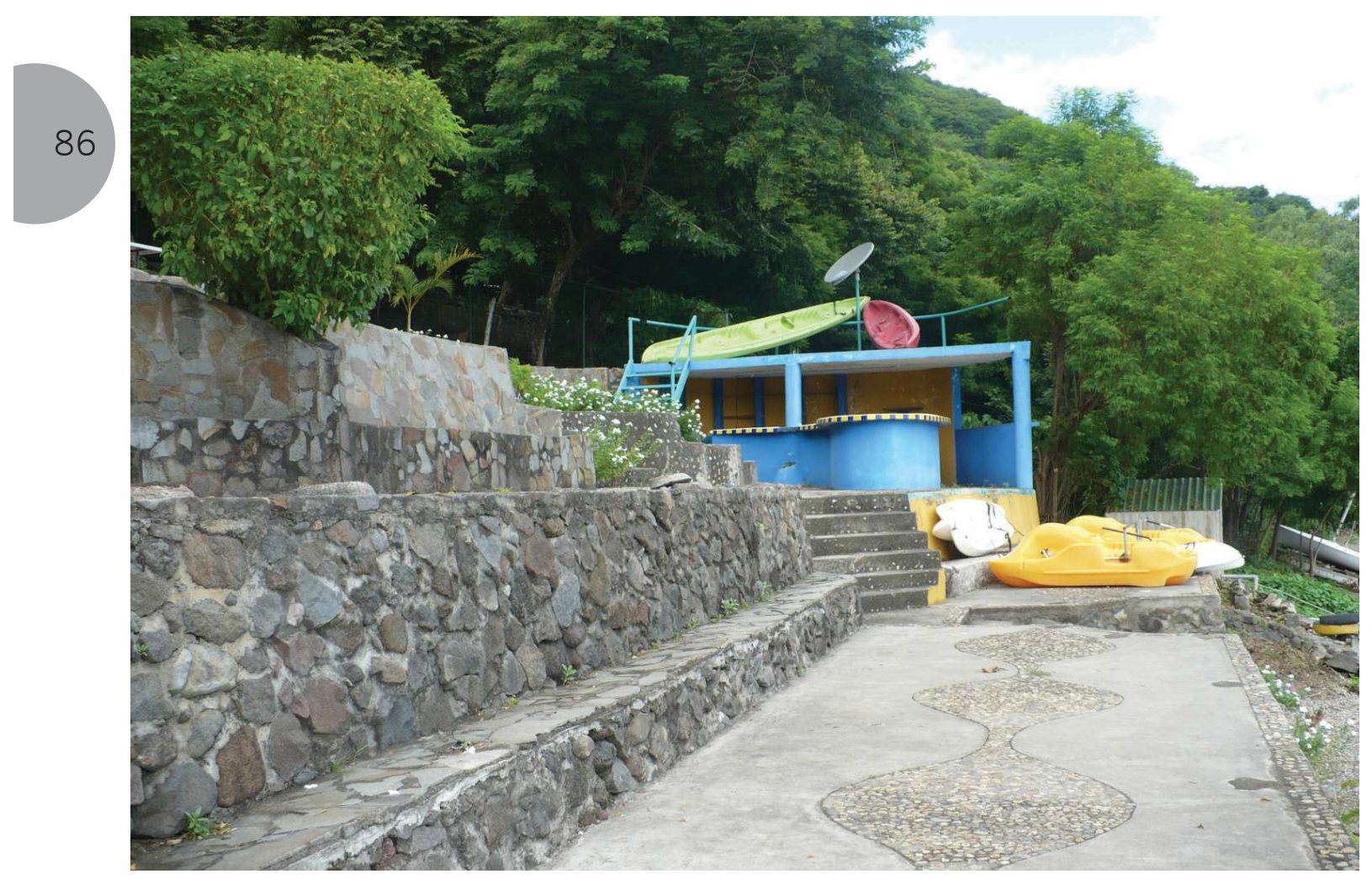

Facilidades recreativas Norome hotel y resort 
En el área costera prolifera la construcción de residencias de verano, hoteles y bares que impactan en las reducidas áreas de playa. La demanda turística crece en el verano a orillas de la laguna, cuando miles de personas visitan las playas cada año, pues se ofertan varios tipos de recreación acuática como navegación, buceo, baño, kayak, entre otros.

\section{Conclusión}

La Reserva Natural Laguna de Apoyo (RNLA) además de formar parte de un complejo escenario volcánico, destaca por su potencial turístico aprovechable en beneficio de los habitantes.

Las laderas internas del cráter, albergan un importante ecosistema terrestre, el bosque trópico seco, que continúa siendo afectado por la explotación que ejercen los pobladores. Este bosque hospeda especies representativas y merece especial atención y protección por estar algunas especies amenazadas o en peligro de extinción, igual suerte sucede al ecosistema acuático de la laguna. sociales y naturales para atenuar procesos erosivos y de sedimentación al cuerpo de agua, así como también para la preservación de las especies en peligro.

\section{Bibliografia}

Asociación de Municipios Integrados por la Cuenca y Territorios de la Laguna de Apoyo de Nicaragua. AMICTLAN.

El Ministerio del Ambiente y de los Recursos Naturales. Boletines. MARENA.

El Nuevo Diario. Nicaragua

Ley General del Medio Ambiente y los Recursos Naturales.

Programa Para la Gestión Ambiental Integral y Sostenible de la Laguna de Apoyo en Nicaragua. Estudio Dinámica Espacial y Temporal de Cobertura y Uso de La Tierra en la RNLA (1972-2007). Compilación a Cargo de Sulim Meyrat Reyes y Otros.

\begin{abstract}
No existen
condiciones de recreación masiva debido a la fuerte pendiente de la costa, la profundidad de la laguna y fragilidad ecosistemica del área de la RNLA.

Se requiere del fortalecimiento de las medidas preve $\mathrm{ntiv}$ a s existentes, frente a las amenazas
\end{abstract}

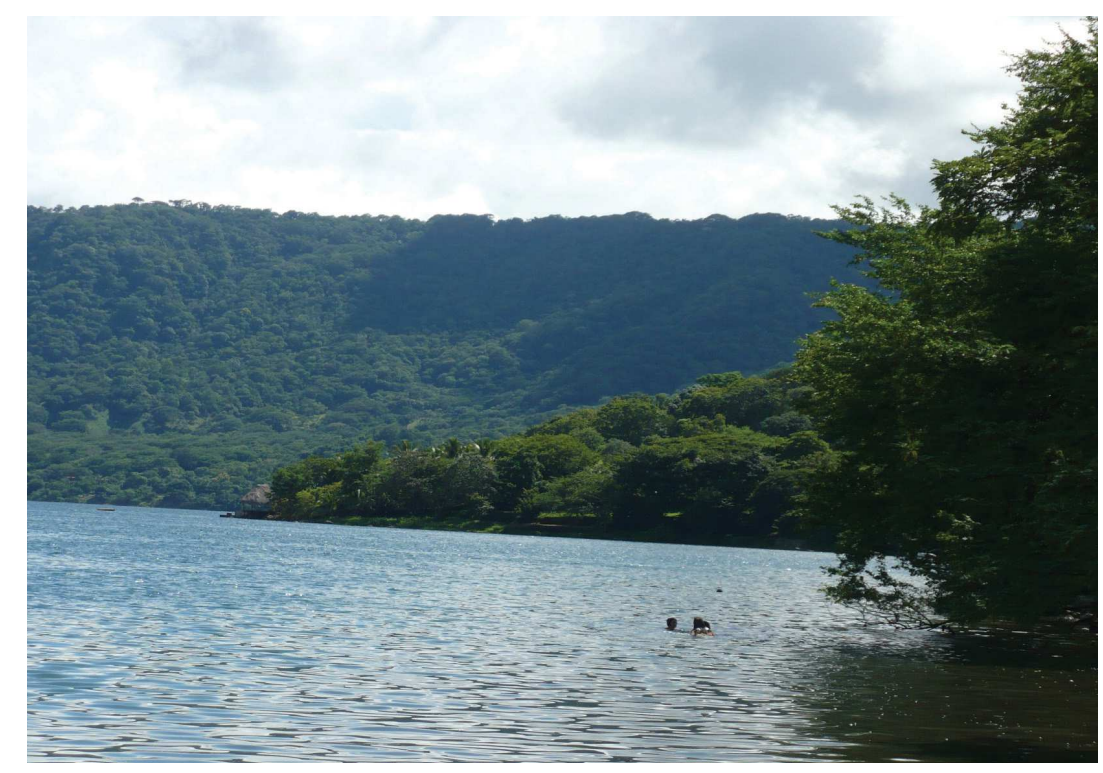

